\title{
DIFFICULT INTUBATION ASSOCIATED WITH THE FOETAL ALCOHOL SYNDROME
}

\author{
BRENDAN T. FINUCANE
}

ABstract

Two case reports are presented in which trachael intubation proved to be extremely difficult. Both of these patients had the distinctive characteristics of the foetal alcohol syndrome. The informed anaesthetist should be aware of this syndrome and its accompanying problems.

ANAESTHETISTS are considered traditionally to be experts in the field of airway management and tracheal intubation. This expertise is gained by familiarity with the anatomy of the airway, and constant practice at intubation. Unheralded difficult intubation is a challenge to the anaesthetist.

The following two case reports describe unanticipated difficult intubation in patients with the foetal alcohol syndrome.

\section{Patient Number One}

A six-year-old male child with known foetal alcohol syndrome presented for repair of a small ventricular septal defect. The child was hyperactive and small for his age, weighing 14 kilograms. He was otherwise healthy. He received morphine sulphate $3 \mathrm{mg}$, droperidol $1 \mathrm{mg}$, and atropine $0.15 \mathrm{mg}$ one hour before operation. Anaesthesia was induced with intramuscular ketamine $6 \mathrm{mg} \cdot \mathrm{kg}^{-1}$. Succinylcholine $15 \mathrm{mg}$ was given intravenously, and orotracheal intubation was attempted with a $5.0 \mathrm{~mm}$ uncuffed tracheal tube. The airway could not be visualized using various sizes of Miller and Macintosh blades. The child had a small mouth, very prominent palatal folds, and limited opening of the mouth. The epiglottis was visible. The arytenoids and vocal cords were not visible at any time. Nasal intubation was attempted but, due to what appeared to be bilateral bony obstruction, this was abandoned. A stilette was used, to no avail. Finally, using the technique described by Rosenberg, et al., ' a 5.0 orotracheal tube was successfully placed in the trachea. This technique involves passage of a stilette through the eye of a tracheal tube; then, directing the stilette beneath the epiglottis toward the glottis, the tube is advanced into the trachea using the stilette as a guide.

Brendan T. Finucane, M.D., Associate Professor, Emory University School of Medicine, Chief, Department of Anesthesiology. Grady Memorial Hospital, 80 Butler Street, S.E., Atlanta, Georgia 30303, U.S.A.

Canad. Anaesth. Soc. J., vol. 27, no. 6, November 1980

\section{Patient Number Two}

A five-month-old child weighing $3 \mathrm{~kg}$ presented for bilateral inguinal hernia repair. The baby was premature, and had a cleft palate and a ventricular septal defect. This baby had the foetal alcohol syndrome. No remarks were made about the airway preoperatively. The child was premedicated with atropine $0.1 \mathrm{mg}$. Anaesthesia was induced with nitrous oxide with oxygen and halothane. Multiple attempts at both oral and nasal intubation ended in failure. The airway was quite difficult to maintain throughout, but with perseverance the procedure was completed without further difficulty.

External examination of the airway did not appear to be abnormal in either of these patients.

\section{Discussion}

References to the foetal alcohol syndrome can be traced back to biblical times. Carpenter ${ }^{2}$ receives credit for publishing the first account of this problem in the medical literature in 1851. In 1968 Lemoine, et al., ${ }^{3}$ from France, described characteristics in the newborn that typify this condition. These observations formed the basis for the designation "foetal alcohol syndrome."

Clarren and Smith recently published a comprehensive account of this condition. They divide the abnormality into four categories: central nervous system dysfunction, growth deficiency, facial abnormalities, and miscellaneous. They also describe some distinctive features of the syndrome which would help anaesthetists to recognize the problem preoperatively. These include short palpebral fissures, and a hypoplastic upper lip with thinned vermilion and diminished to absent philtrim. The face may be further altered by maxillary and mandibular hypoplasia.

As in these two cases reported, many of these children also suffer from growth retardation and congenital cardiac abnormalities. The practicing anaesthetist should be aware of this condition, 
which is by no means rare. Clarren and Smith also infer that less severe forms of the syndrome are known to occur. A proportion of difficult tracheal intubations are probably due to attenuated versions of this condition.

\section{REFERENCES}

1. Rosengero, M.B., LeVesque, P.R. \& Bourke, D.L. Use of $\mathrm{LTA}^{\oplus}$ kit as a guide for endotracheal intubation. Anesth. Analg. 56: 287-288 (1977).
2. Carpenter, W.V. Use and abuse of alcoholic liquors. Boston: Crosby \& Nichols for Mass. Tem. perance Society (1851).

3. Lemoine, P., Haronsseau, H., Borteryu, J.P. \& Menuet, J.C. Les enfants de parents alcooliques: anomalies observees a propos de 127 cas. Quest Med 25: 476-482 (1968)

4. Clarren, S.K. \& Smith, D.W. The fetal alcohol syndrome. N.E.J.M. 298: 1063-1067 (1978).

\section{RÉSUMÉ}

On rapporte deux cas d'intubation trachéale extrêmement difficiles survenus chez des enfants présentant les caractéristiques du syndrome alcoolique fétal. Plusieurs anomalies peuvent être observées chez des enfants nés de parents alcooliques (dysfonction du système nerveux central, retard de croissance, anomalies oromaxillo-faciales, etc.) et l'anesthésiste devrait être conscient de l'existence de ce syndrome et de la possibilité de problèmes chez ceux qui le présentent. 